While Stan may have concluded early on that he was not by nature a litigator, he was nevertheless a lawyer who made good use of his training and law degree. He was a member of the United States Supreme Court Bar, for eight years chairman of the Ombudsman Committee of the American Bar Association's Administrative Law Section, and for 40 years a member of the Santa Barbara County Bar Association. While teaching he was a mentor and inspiration to many local attorneys, and after retirement was lauded by the local bar association for his pro bono work with indigent felony defendants. In 2002 he received the Santa Barbara County Bar Association's Richar Abbe Humanitarian Award "for his lifelong devotion to humanitarian service."

I first met Stan in 1964, in Washington, D.C., where he was completing his Congressional Fellowship year and I was returning from my first year at UCSB to complete research on a project for the Brookings Institution. We arranged to meet for dinner, and then go to a baseball game at what later became RFK Stadium. I brought a friend from Brookings, and when the three of us got to the stadium we found two empty seats at one end of our row, and one at the other end. Stan stood in front of the row and asked if everyone could move over one seat, so that the three of us could sit together. It was a reasonable request, gently tendered, and they did. That was the Stan Anderson I came to know for 45 years, my model citizen. Were it not for problems of scale that require collective action, a libertarian community composed of Stan Andersons might actually work. Stan is survived by his wife Mary, his son and daughter-inlaw Stefan and Chi, his brother Bob, and an extended family beyond counting.

John E. Moore Professor Emeritus University of California, Santa Barbara

\section{ALEX DRAGNICH}

doi:10.1017/S1049096509990886

Following a period of declining health, Alex Dragnich died of pneumonia on August 10, 2009, at the age of 97. His mind remained sharp and his pen vigorous until almost his death.

He was especially notable for having, in effect, two careers. The first: teacher and scholar. The second, after retiring: scholar and commentator on public affairs. Each of these careers spanned 30 years. He published more after he had retired than he had before retiring, six of his eleven books, for example. During his second career, he not only wrote books, but also authored journal and op-ed articles, as well as letters to the editor. He participated frequently in Washington, D.C., policy seminars and appeared on TV programs.

Dragnich's life was the classic American success story. He was the son of Serbian immigrants. Difficult as it is to believe, he really did grow up in a log cabin in the Pacific Northwest. He didn't start school until he was nine, following a visit from the truant officer, who explained to his parents about compulsory education. $\mathrm{He}$ eventually graduated Phi Beta Kappa from the University of Washington and earned a Ph.D. at the University of California, Berkeley.

DuringWorldWar II he served as a social science analyst for the Department of Justice and the Office of Strategic Services. After teaching at Case Western Reserve, he became Cultural Attache and Public Affairs Officer at the American Embassy in Belgrade, Yugoslavia, from 1947 to 1950. This post shaped his entire career.

The chancellor of Vanderbilt University, Harvie Branscombe, on a mission for the U.S. government, met Dragnich in Belgrade. He was so impressed that he offered him an appointment as associate professor, should he decide to leave government service. Two years later, Dragnich went to Vanderbilt, teaching there from 1950 to 1978.

Branscombe sought advice from Dragnich on recruiting a chair who could build a reputable political science department. Avery Leiserson was brought from the University of Chicago to accomplish this mission. During more than a decade as chair, Leiserson worked closely with Dragnich. When he retired as chair, Dragnich took over from 1964 to 1969 . The two of them built a department of note. In 1970 Dragnich received the Thomas Jefferson Award for distinguished service to Vanderbilt.

This was just one of many awards and honors. He was Chester Nimitz Professor at the U.S. Naval War College in 1959-6o, a research fellow at the Hoover Institution in 1978-81, and a distinguished lecturer at Washington and Lee University in 1982. In 2002 he received the Yugoslav Star, First Class, medal from the presi- dent of Yugoslavia in recognition of his efforts to enhance Serbia's image in the United States. He served as president of the Southern Political Science Association and as vice president of the American Political Science Association.

He did not court controversy, but wasn't afraid to go against the flow. His first book, Tito's Promise Land: Yugoslavia (1954), was unfashionable. Many students of international affairs had come to view Tito as leader of a "third world" grouping, bridging the cold war chasm between the United States and the Soviet Union. Dragnich, however, understood fully the oppressive nature of the Tito regime, having himself lived under surveillance during his years in Yugoslavia. He published his final book, Serbia Through the Ages (2004) at age 92.

His comparative politics textbook, Major European Governments, was widely adopted, going through nine editions over more than a third of a century. His considerateness is attested to by the harmonious relations with Jorgen Rasmussen and Joel Moses, who became coauthors in the later editions.

In his personal relations he was mild and unassuming, leading by example, rather than by command. Nonetheless, he was fervent in support of his basic values.

He was predeceased by his wife and one son and survived by a son, a daughter, and three grandchildren. He took great pleasure in his family. Clichés, by definition, are overused. They sometimes provide, however, the most apt assessment. Alex Dragnich was, indeed, a gentleman of the old school.

Jorgen Rasmussen Distinguished Professor Emeritus Iowa State University

\section{ROBERT W. JACKMAN}

doi:10.1017/S1049096509990898

Robert W. Jackman, Distinguished Professor of Political Science at the University of California, Davis, died peacefully in San Francisco on October 8, 2009, after a long, courageous struggle with pancreatic cancer.

Bob was born on October 31, 1946, in Oamaru, New Zealand, the first-born child of two school teachers, David and Helen Jackman. His father was a veteran of the North African campaign in WWII, and he and his new wife sought a quiet life teaching in rural Maori communities. Bob's 
early years were thus spent among the Maori, living in homes without many modern amenities, and experiencing the self-sufficiency and mutual support that characterized life in New Zealand's remote Maori communities. He recalled with fondness that he did not wear shoes until he was eight years old. His parents were passionate about education and music, and those were gifts that he kept throughout his life.

In 1962, Bob's parents moved their family of four children to Auckland, and in 1963 his father died suddenly of a brain tumor. Bob was shattered by his father's death, but he proceeded with his education, graduating from the University of Auckland in 1968 with a BA in history and political studies. As an undergraduate, he was active in the Labour Party and he was a prominent student organizer of symposia, talks, and protests against the Vietnam War. Despite his distaste for American foreign policy, he admired American social science and his ambition was to undertake graduate study in political science in the United States. He was accepted into the political science graduate program at the University of Wisconsin-Madison with a teaching assistantship, and, after working for four months in a bread factory to earn the money for the journey, Bob arrived in Madison, Wisconsin, in August 1968. He was joined there by his sweetheart from New Zealand, Mary Peretz, and they were married that September just as Bob began his graduate studies.

Bob was awarded the Ph.D. in December 1972, shortly after he had joined the faculty of the political science department at Michigan State University. In 1973, he and Mary moved their residence to Ann Arbor, Michigan, so that Mary could accept a position in the sociology department at the University of Michigan (Mary could not drive at the time). Bob maintained the 6o-mile commute to East Lansing until July 1989, when he and Mary moved to the University of California, Davis, with their two young children, Rachael (born in 1977) and Saul (born in 1983). During his years at Michigan State, Bob did not let the lengthy and sometimes hazardous commute interfere with his active involvement in the political science department, maintaining close relationships with faculty and students and playing a central role in the governance and intellectual life of the department, where he was deeply respected as a colleague, teacher, and scholar.
Over the course of his career, Bob was the author or coauthor of four books and more than 40 papers, most of which were published in the most prominent journals in political science and sociology. His work lay at the intersection of political science and sociology, driven by questions about political institutions, political behavior, and social inequality. $\mathrm{He}$ focused primarily on the macro level and he developed a prodigious knowledge and understanding of the issues that impede democratic representation and social equality in nation states, as well as of the methodological hurdles that confront the statistical analysis of crossnational data. At the same time, he maintained an active interest in the political attitudes and behavior of individuals and the structural and institutional factors that shape individuals' political orientations and behavior.

His initial work sought to deepen our understanding of the relationship between the economic and political development of nation states and social inequality. This research resulted in Bob's first book, Politics and Social Equality (Wiley, 1975). This book was important on both theoretical and methodological grounds. In a systematic, cross-national, statistical analysis, Bob challenged the received wisdom that the advent of democratic government brings social and economic equality in its trail. His analyses, instead, identified the significance of economic growth in leading to some diminution of economic inequality and underscored the limited degree of change in economic inequality that had been achieved in the world. These analyses were built on a more find-grained definition of the empirical elements of democratic government that pointed to the multifaceted, fragile, and malleable nature of the democratic form. The theoretical contribution of the book is both in Bob's careful exposition of the flaws in prior work and in his refinement of a complex model of political structures and social inequality. One reviewer compared the book to the style of Simenon's Inspector Maigret in which suspects were examined and either cast aside or saved for the ultimate dénouement. This line of research was developed in further work over subsequent years and brought a series of collaborative papers with sociologist Kenneth A. Bollen, several of which were published in the American Sociological Review.
Bob also maintained a strong interest in the political attitudes and behavior of individuals. As a graduate student, one of his early published papers was on support for democratic principles among political elites and the mass public in the United States, and later he worked with his wife, Mary R. Jackman, on a project that explored the popular American understanding and interpretation of social class, as a component of Americans' identity and political awareness. This research culminated in the publication of their joint book, Class Awareness in the United States (University of California Press, 1983).

Over his career, Bob's research turned increasingly to the effects of the political institutions of the state on patterns of political behavior. The evident failure of numerous new states that followed the wave of decolonization sparked an interest in state capacity. In Power without Force (University of Michigan Press, 1993), Bob undertook a searching examination of the interrelated ideas of political development and state capacity. The overall thrust of the book's argument is that the persistent exercise of power within an accepted, legitimate institutional framework is the hallmark of political capacity, and what makes institutions legitimate is their repeated ability to resolve conflicts without resorting to force.

Bob's work on political institutions led him to be skeptical about an old idea that had revisited social science and taken it by storm: that variations in political behavior are best explained by idiosyncratic, cultural forces rather than by the structural and institutional constraints that frame the lives of rational, goal-oriented individuals. He became increasingly interested in the nature of rationality and the way in which variations in the institutional enactment of democracy affect the political behavior of elites and the mass public. $\mathrm{He}$ wrote a number of papers exploring these topics, and in 2004 he published a book with his former student, Ross A. Miller, Before Norms: Institutions and Civic Culture (University of Michigan Press). The book offers a trenchant analysis of the explanatory merits of theories of political culture versus theories that focus on the preferences of calculating individuals who work to pursue their interests within structural and institutional constraints. The book emphasizes the endogeneity of the mass political behaviors that become known as "political culture." The first 
chapters of the book present a crisp, penetrating analysis of the shortcomings of prevalent theories about the exogenous impact of political culture and social capital, as well as a sharp empirical assessment of the measurement of social capital. This includes a demonstration that while league bowling may have been declining in the United States (then widely accepted as an indicator of the ebbing of social capital), there had been upsurges in other kinds of voluntary association across a wide variety of activities. The second half of the book explores the empirical impact of political institutions on political behavior by examining the effects of variation in political institutions on the rise of rightwing parties in Europe and on political participation.

Bob's contributions as a scholar and teacher were recognized with a number of awards. He was the recipient of fellowships from both the Guggenheim Foundation and the Center for Advanced Study in the Behavioral Sciences at Stanford, as well as two awards from the National Science Foundation. In 1988, Bob's achievements as a scholar and teacher were recognized by Michigan State University with the Distinguished Faculty Award. The breadth of Bob's recognition is perhaps best shown by the fact that between 1995 and 1998 he was simultaneously on the editorial boards of both the American Political Science Review and the American Sociological Review. Students and colleagues alike relied on him as a seemingly inexhaustible source on a broad array of intellectual and methodological issues, and his knowledge was always shared with generosity, incisiveness, and humility.

Bob's contributions to the Davis department are well known to his colleagues. He was committed to a cross-national, comparative perspective in his field of comparative politics. Although his own contributions to the field emphasized the importance of institutions, he was committed as well to the value of comparative behavioral work, and enthusiastically backed several hiring decisions that emphasized that side of the subfield. As a direct result of his leadership of the comparative field, the Davis department has porous boundaries between traditional subfields, and comparativists regularly collaborate with Americanists and international-relations scholars. Since Bob joined the Davis department, it has grown significantly in its vitality, intellec- tual energy, and collaborative spirit. Bob Jackman's contributions were critical to this progress, although if asked to assess his own importance to the department, his one-word response would likely have been, "exiguous." Bob was prized as a mentor by both graduate students and junior faculty. He spent many hours working individually with students and colleagues on research problems and career-related issues. His generosity and expansive intellect were immediately apparent to all who interacted with him. His teaching in the department spanned courses on comparative politics, methods, and American public opinion. A standing joke toward the end of the quarter when he was teaching public opinion was to ask which "level of conceptualization" he had managed to cover by that point in the course. His invariant response was a smile and say, "Still on level one." His unwavering commitment to scholarly principles, coupled with his broad and incisive intellect, communal generosity, and down-to-earth good humor, contributed significantly to the growth of the political science department at UC Davis.

Over the last two and a half years of his life, Bob fought his illness with the same quiet determination and dry humor that he had brought to all his endeavors. He strove to continue living his life as fully as he could, savoring the last undergraduate course that he taught (against medical advice) in the fall of 2008, continuing with scholarly collaborations, and maintaining his generous availability as a colleague and mentor.

But Bob was more than a political scientist. He was a lover of music who delighted in his regular attendance at concerts with the San Francisco Symphony. He was knowledgeable about automobiles and an avid reader of Car and Driver, making him much sought after for advice when it came time to buy a car. He loved to collect and work with old hand tools, which he often picked up after a tour through the listings on eBay. He retained the sense of practical self-sufficiency that he had acquired from his rural New Zealand childhood, and he got great satisfaction from all manner of carpentry, plumbing, and electrical projects around the home, always executed with finesse. He relished the physical beauty of California, especially the northern coast in Big Sur, San Francisco, and Mendocino, where he spent many happy days with his fam- ily and friends. He set great value in his friendships and he was a steadfast, loyal, and generous friend. In his personal and his professional life, he was a person of unusual warmth, self-deprecation, dry, understated humor, and quiet but fierce determination. He will be dearly missed by his family, colleagues, and friends, and by the many past and current graduate students of whom he was so proud.

Bob is survived by his wife Mary Jackman, professor of sociology at UC Davis; his daughter Rachael in San Francisco and son Saul in Palo Alto; his son-in-law Matt Munz in San Francisco; his brother and sister-in-law David and Margaret Jackman in Australia; his sister and brotherin-law Marian and John Vickerman and sister Helen Jackman in New Zealand; his brother-in-law and sister-in-law Paul Peretz and Jean Schroedel in Claremont, California; his niece and eight nephews in New Zealand, Australia, and California; and his mother-in-law Lil Peretz who migrated from Israel to Davis in 2001 with her (now deceased) husband Eddie to live with Mary and Robert.

A fund has been established in Bob's memory that will support the research activities of graduate students. Gifts should be made out to UC Regents and sent to: The Robert Jackman Memorial Fund, UC Davis, Department of Political Science \#106o, One Shields Avenue, Davis, CA 95616.

A memorial was held for Bob in Davis on December 6, 2009. There will also be a panel in honor of Bob's life, work and friendship at the Midwest Political Science Association meetings in Chicago in April 2010

Randolph M. Siverson
University of California, Davis
Walter J. Stone
University of California, Davis

\section{LORAN B. SMITH}

doi:10.1017/S1049096509990904

\section{Introduction, by Dr. Steven Cann, Washburn University}

Dr. Loran B. Smith passed away in Topeka, Kansas, on July 24, 2009. He was born on July 23, 1946. He was the son of Gordon T and Edith A (Hibbard) Smith of Medford, Massachusetts. Loran received his bachelors degree at Salem State College (Massachusetts) in 1968, a masters from 